\title{
TU/e EmonONEN

\section{A combined experimental and numerical examination of welding residual stresses}

\section{Citation for published version (APA):}

Rikken, M., Pijpers, R., Slot, H., \& Maljaars, J. (2018). A combined experimental and numerical examination of welding residual stresses. Journal of Materials Processing Technology, 261, 98-106.

https://doi.org/10.1016/j.jmatprotec.2018.06.004

\section{Document license:}

TAVERNE

DOI:

10.1016/j.jmatprotec.2018.06.004

Document status and date:

Published: 01/11/2018

\section{Document Version:}

Publisher's PDF, also known as Version of Record (includes final page, issue and volume numbers)

\section{Please check the document version of this publication:}

- A submitted manuscript is the version of the article upon submission and before peer-review. There can be important differences between the submitted version and the official published version of record. People interested in the research are advised to contact the author for the final version of the publication, or visit the $\mathrm{DOI}$ to the publisher's website.

- The final author version and the galley proof are versions of the publication after peer review.

- The final published version features the final layout of the paper including the volume, issue and page numbers.

Link to publication

\section{General rights}

Copyright and moral rights for the publications made accessible in the public portal are retained by the authors and/or other copyright owners and it is a condition of accessing publications that users recognise and abide by the legal requirements associated with these rights.

- Users may download and print one copy of any publication from the public portal for the purpose of private study or research.

- You may not further distribute the material or use it for any profit-making activity or commercial gain

- You may freely distribute the URL identifying the publication in the public portal.

If the publication is distributed under the terms of Article 25fa of the Dutch Copyright Act, indicated by the "Taverne" license above, please follow below link for the End User Agreement:

www.tue.nl/taverne

Take down policy

If you believe that this document breaches copyright please contact us at:

openaccess@tue.nl

providing details and we will investigate your claim. 


\title{
A combined experimental and numerical examination of welding residual
} stresses

\author{
Maarten Rikken ${ }^{\mathrm{a}, \mathrm{b}, *}$, Richard Pijpers ${ }^{\mathrm{b}}$, Henk Slot $^{\mathrm{b}}$, Johan Maljaars ${ }^{\mathrm{b}, \mathrm{c}}$ \\ a Arup, Infrastructure, The Netherlands \\ b TNO, Department of Structural Reliability, The Netherlands \\ ${ }^{\mathrm{c}}$ Eindhoven University of Technology, Department of Built Environment, The Netherlands
}

\section{A R T I C L E I N F O}

\section{Keywords:}

Dilatometer tests

Tensile tests at elevated temperature

Thermo-mechanical coupled finite element analysis

Crack compliance method

Residual stresses

\begin{abstract}
A B S T R A C T
This study examines residual stresses in bead-on-plate welded specimens in transverse direction over the thickness of the plate, using a combination of experimental and numerical procedures. Dilatometer and tensile tests were used to determine the phase transition temperatures with associated volumetric strains and the stressstrain relationships of the S355G10 + M base material. Temperature profiles have been measured during welding. Residual stresses of the base plate and the welded specimen were determined with the crack compliance method. The thermal (finite element) simulations used the measured material parameters as input and the experimentally obtained temperature profiles were used as calibration data for the welding process. The residual stress predicted by the subsequent mechanical simulations were compared with the measured residual stress and a good agreement was obtained. This study demonstrates the importance of using correct phase transition temperatures and volumetric strains in simulations of residual stresses.
\end{abstract}

\section{Introduction}

Residual stresses are internal, self-balanced stresses in a solid material without the presence of external loads. These stresses may result from various manufacturing processes including plastic deformation and/or temperature gradients and phase transformations. Arc welding introduces severe temperature gradients, promoting non-uniform thermal expansion during heating. The mechanical material properties of steel decay at elevated temperature, resulting in plastic strains and distortions at corresponding temperature levels. Contraction of the expanded regions during cooling is restrained by external constraint conditions and surrounded, cooler material, resulting in residual stress formation. The thermo-mechanical rolling process plastically deforms steel during the manufacturing process in the stable austenite temperature regime. Thermal gradients arise during the heat treatment when it is cooled down in air to room temperature. This study considers the process of residual stress formation caused by arc welding and thermo-mechanical heat treatments.

A wide range of welding residual stress formation studies is available in literature whereby researchers have been using decoupled thermo-mechanical finite element modelling techniques. Most of the thermal analyses use the heat source model of Goldak et al. (1984); Goldak and Akhlaghi (2005) to model the presence of the weld arc on base and weld material. Goldak proposed to use a transient, volumetric heat flux distribution of a moving heat source. The mechanical analyses employs the transient temperature results from the thermal analysis to simulate residual stress formation. Arc welding involves often the repetitive deposition of molten filler material until the desirable joint has been manufactured. This repetitive character of welding and the exposure to cyclic temperature ranges arises the necessity of choosing adequate material models in the numerical procedures for each individual welding configuration. Isotropic hardening models have been employed in most studies (Van der Aa, 2007) and use a plasticity model derived from steady-state tensile tests at elevated temperatures. Cyclic, thermo-mechanical loading conditions during welding require the implementation of a kinematic material model to include the Bauschinger effect. Muransky et al. (2012) showed that this effect is in particular important for multi-pass welding. Moreover, strain rate dependent material models may become important in welding simulations (Depradeux and Coquard, 2017). Muliti-pass welding exposes the base material and the ground weld beads to extended times at elevated temperature, that can reduce the magnitude of the internal stresses due to creep (Muransky et al., 2015). The mechanical material properties of base and weld material are largely controlled by the non-uniform peak temperature and cooling rate during a welding thermal cycle (Bhadehsia, 2006). Gao (2014) and Kaushik Dutta (2015) showed that

\footnotetext{
* Corresponding author at: Arup, Naritaweg 118, 1043 CA, Amsterdam, The Netherlands.

E-mail address: maarten.rikken@arup.com (M. Rikken).
} 
the phase transformation behavior during cooling can be studied experimentally and implemented in the finite element program to study the volumetric strain development.

From this overview, it follows that the material properties of steel are temperature and exposure time dependent. They differ between material grades and batches and between welding procedures. These differences may have a pronounced effect on the formation of residual stress. For calibration and validation of numerical models aiming at the simulation of residual stress, it is therefore important to use experimental tests data of the specific batch and weld procedure. In many numerical simulation studies however, material properties have been taken from other sources or from neural networks (Van der Wolk et al., 2002a,b) (Guo et al., 2009). Two comparable studies (Wohlfart et al., 2012) (Shan et al., 2009) for residual stress formation in bead-on-plate welded specimens, the subject of this paper, studied the residual stress distribution without extensive material research and without throughthickness residual stress validation by means of experiments. The current study considered detailed metallurgical examinations of base material S355G10 + M and bead-on-plate welding experiments and used it as input, calibration and validation data for the numerical models. The reported experimental procedures can be used directly for comparable weld configurations and materials. An adaptation of the material model may be necessary for other types of joints.

This study adopted the three simulation steps indicated by Goldak and Akhlaghi (2005). The first step is to determine the required material characteristics for the welding simulations. This study applied two experimental procedures: dilatometer tests for expansion and contraction characteristics and tensile tests at elevated temperature for the mechanical resistance. Other, general sources were used for the less decisive or less uncertain (thermal) material properties. In the second step, temperature measurements during bead-on-plate weld experiments have been obtained and used to calibrate a 3D, transient temperature analysis using Abaqus CAE (SIMULIA, 2012). In the third step, a numerical mechanical analysis was carried out, using the results of the two prior analyses and used to study the residual stress state. These numerical results were compared with crack compliance measurement data from the welded bead-on-plate specimens. The residual stress in the $50 \mathrm{~mm}$ thick base plate, introduced by the thermo-mechanical heat treatment, has been examined with the experimental procedure too. Fig. 1 presents a graphical representation of the research set up.

\section{Material analysis}

The material analysis in this section provides understanding of the response during a thermal cycle, introduced by the welding procedure and it served as input for the thermo-mechanical welding simulations.

\subsection{As-received material}

The base material plate of grade S355G10 + M with a thickness of $50 \mathrm{~mm}$ was manufactured with a thermo-mechanical rolling treatment. The average grain size and Vickers Hardness according to ASTM International (2012) and ASTM International (2016) were $22.1 \mu \mathrm{m}$ and $175 \mathrm{HV}$, respectively. The microstructure consisted of coarse pearlite grains in a ferritic matrix. The bead-on-plate weld was made with a flux-cored wire Union BA 70 with a diameter of $1.2 \mathrm{~mm}$. The chemical

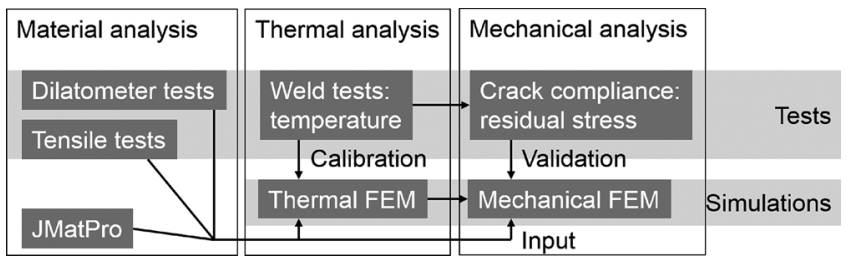

Fig. 1. Research set up. composition, provided by the manufacturer, is presented in Table 1 . The fusion zone is a mixture of base and wire metals. Because the fusion zone is relatively small and the chemical composition of the wire agrees reasonably with that of the base plate, the base plate material was further investigated and considered representative for the entire specimen (including fusion and heat affected zones).

\subsection{Heat affected base material}

The thermal expansion and shrinkage behavior of the base material was determined with a Bähr thermoanalysis DIL805 dilatometer. Small scale specimen of $2 \times 2 \times 10 \mathrm{~mm}$ were exposed to a predefined thermal cycle, consisting of heating to $1000{ }^{\circ} \mathrm{C}$ with a constant heating rate of $10^{\circ} \mathrm{C} / \mathrm{s}$ and subsequently cooling to room temperature with cooling rates ranging between 0.1 and $200{ }^{\circ} \mathrm{C} / \mathrm{s}$. The dilatation curves are presented in Fig. 2. The figure demonstrates that the phase start and finish temperature decay at increasing cooling rates.

The total thermal strain comprises two components: linear thermal expansion and a volumetric strain component during solid-solid state phase transformations. The average, linear thermal expansion coefficient derived from the slope of the dilatation curves was equal to $1.5 \mathrm{E}$ $05{ }^{\circ} \mathrm{C}^{-1}$ for the microstructures at room temperature (a mixture of ferrite with other constituents) and $2.2 \mathrm{E}-05^{\circ} \mathrm{C}^{-1}$ for austenite. The phase transformation temperatures were estimated from the transitions between these two expansion coefficients. The phase start and finish temperatures during heating with $10^{\circ} \mathrm{C}$ were equal to $\mathrm{A} 1=735^{\circ} \mathrm{C}$ and $\mathrm{A} 3=884^{\circ} \mathrm{C}$, respectively. These temperatures were lower at subsequent cooling and decreased with increasing cooling rates. A variation in heating rates has not been considered, because the solid-solid phase transformations during heating are of minor importance for the weld simulation due to the relatively low strength and stiffness characteristics above the $\mathrm{A} 1$ temperature.

The microstructure and average Vickers Hardness numbers were obtained after each dilatation test, Fig. 3. This figure demonstrates that an increasing cooling rate supports the formation of hard and brittle microstructures. The figure further indicates fine pearlite particles dispersed into a ferritic matrix for a cooling rate of $1{ }^{\circ} \mathrm{C} / \mathrm{s}$ and bainite and some martensite for cooling rates above $30^{\circ} \mathrm{C} / \mathrm{s}$.

Stress-strain curves were determined at temperatures ranging between 20 and $1000{ }^{\circ} \mathrm{C}$ using a Gleeble 3800 system. The specimens were taken from the base plate in the near surface region, with the force applied parallel to the rolling direction. The test specimens were first heated to the desired temperature level and then subjected to a displacement with a constant rate of $0.05 \mathrm{~mm} / \mathrm{s}$. An extensiometer measured the deformation during the test. Fig. 4 presents the engineering stress-strain curves. Necking outside the range of the extensiometer occurred for the temperature levels of 300 and $600{ }^{\circ} \mathrm{C}$, so these curves are incomplete. A clear yield plateau is absent at elevated temperature and strength and stiffness properties decrease whereas the strain at rupture increases at increasing temperatures. Table 3 provides the results of the tests (first four columns). The strength and stiffness properties at temperatures above the liquidus temperature level were not measured but considered as negligibly small.

Less important or less scattered material properties are taken from other sources. The software Java-Based Material Properties (JMatPro) (Sente Software Limited, 2005) provides thermal-physical material properties as a function of material type and temperature input by combining statistical models based on a preprogrammed database with empirical and theoretical models (Saunders et al., 2003). A temperature of $800{ }^{\circ} \mathrm{C}$ was considered for the current application, representative of the final rolling treatment during production. The Poisson ratio for the solid state acquired by JMatPro is presented in the last column of Table 2. The Poisson ratio for the liquid phase is set to 0.495 , mimicking (almost) incompressible material. Fig. 5 provides the density, specific heat and thermal conductivity as a function of the temperature as acquired by the software. Goldak and Akhlaghi (Goldak and 
Table 1

Chemical composition (mass \%).

\begin{tabular}{|c|c|c|c|c|c|c|c|c|c|c|c|c|c|c|}
\hline & $\mathrm{C}$ & Mn & $\mathrm{Si}$ & $S$ & $\mathrm{P}$ & $\mathrm{Al}$ & $\mathrm{N}$ & $\mathrm{Cu}$ & $\mathrm{Ni}$ & $\mathrm{Cr}$ & $\mathrm{Nb}$ & $\mathrm{Ti}$ & As,Sn,Mo,V,B & $\mathrm{Fe}$ \\
\hline Base & 0.07 & 1.51 & 0.302 & 0.002 & 0.013 & 0.031 & 0.005 & 0.228 & 0.210 & 0.027 & 0.026 & 0.017 & $\leq 0.002$ & rest \\
\hline Wire & 0.06 & 1.40 & 0.450 & $\leq 0.02$ & $\leq 0.02$ & & & & & & & & & rest \\
\hline
\end{tabular}

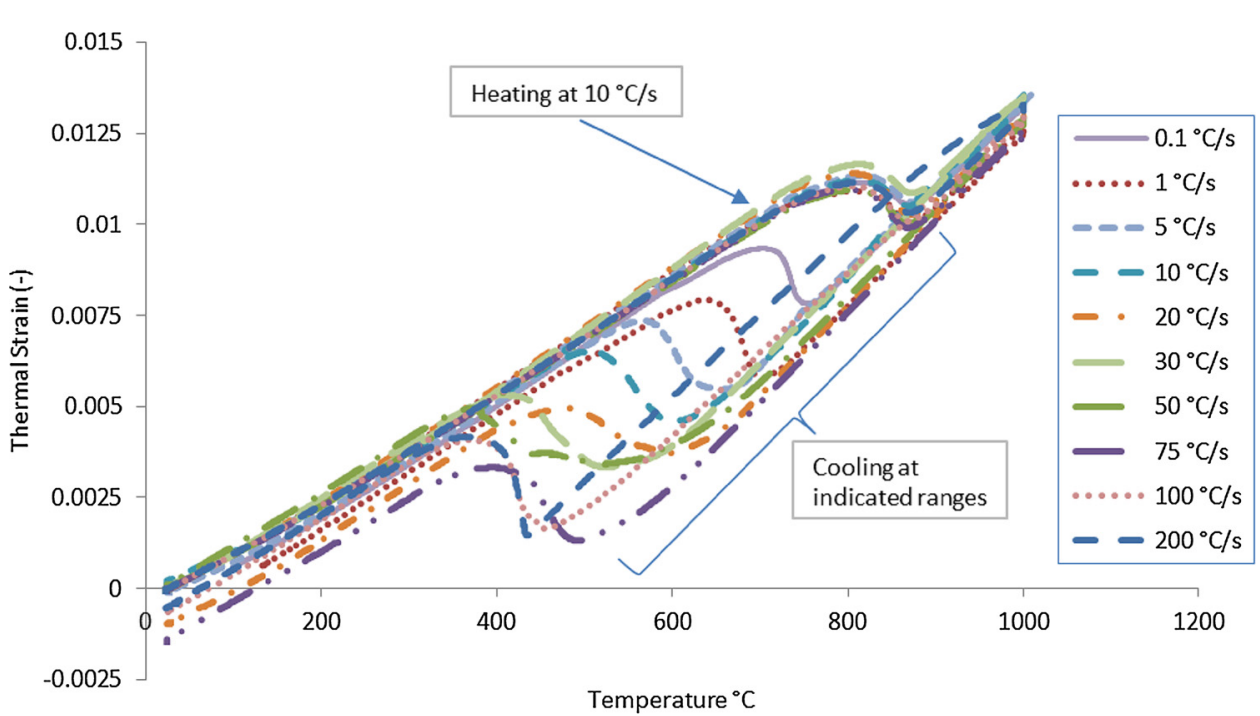

Fig. 2. Dilatometer curves for different cooling rates.

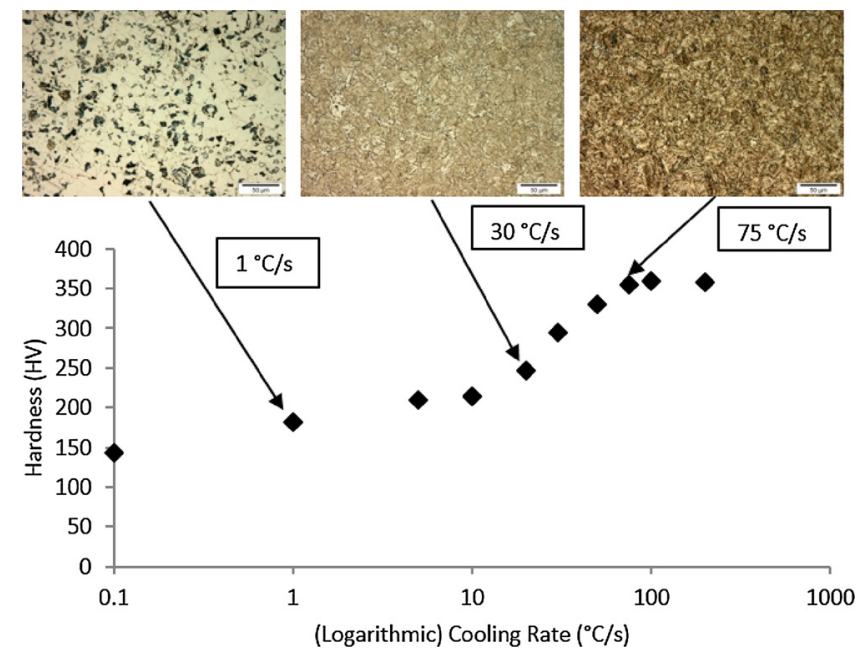

Fig. 3. Vickers Hardness characteristics measured at room temperature after heating and cooling for each dilatation curve with three microscopic images at three cooling rates.

Akhlaghi, 2005) provide parametric equations for the solidus and liquidus temperature levels of carbon steels based on their chemical composition, resulting into a liquidus temperature equal to $1530^{\circ} \mathrm{C}$ for the current application.

\section{Thermal analysis}

The transient temperature distribution in the bead-on-plate welded specimens were studied using experimental and numerical procedures and the thermal material data.

\subsection{Thermal experiments}

Four bead-on-plate welded specimens were manufactured with a gas

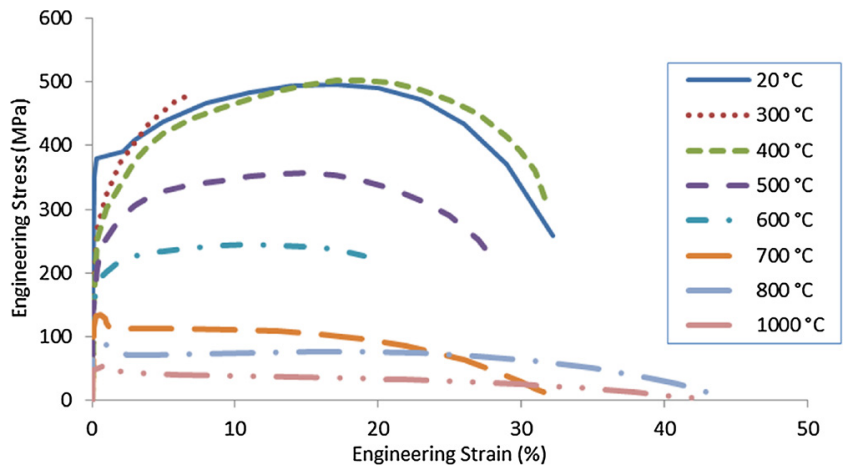

Fig. 4. Engineering stress-strain curves for the base material S355G10 + M at several temperature levels.

Table 2

Temperature dependent mechanical material properties.

\begin{tabular}{lllll}
\hline Temperature $\left({ }^{\circ} \mathrm{C}\right)$ & $\begin{array}{l}\text { Modulus of } \\
\text { Elasticity (GPa) }\end{array}$ & $\begin{array}{l}\text { Yield } \\
\text { Strength } \\
(\mathrm{MPa})\end{array}$ & $\begin{array}{l}\text { Tensile } \\
\text { Strength } \\
(\mathrm{MPa})\end{array}$ & $\begin{array}{l}\text { Poisson } \\
\text { Ratio } \\
(-)\end{array}$ \\
\hline 20 & 210 & 390 & 496 & 0.29 \\
300 & 193 & 270 & 485 & 0.30 \\
400 & 183 & 252 & 502 & 0.31 \\
500 & 171 & 206 & 358 & 0.31 \\
600 & 158 & 181 & 245 & 0.31 \\
700 & 143 & 132 & 135 & 0.32 \\
800 & 127 & 82 & 88 & 0.32 \\
1000 & 106 & 50 & 59 & 0.35 \\
$\geq 1500$ & 0.1 & 0.1 & 0.1 & 0.495 \\
\hline
\end{tabular}

metal arc welding procedure, Fig. 6a. Welding was performed perpendicular to the rolling direction. The weld torch moved along the workpiece with a speed of $6.3 \mathrm{~mm} / \mathrm{s}$ and the current and voltage levels were equal to 247 amperes and $28.4 \mathrm{~V}$, respectively. The plates were not constrained during the welding process. Weld run on and run off 
Table 3

Input parameters for Goldak's heat source model.

\begin{tabular}{lllllll}
\hline$a$ & $b$ & $c_{1}$ & $c_{2}$ & $\eta$ & $f_{f}$ & $f_{r}$ \\
\hline $8 \mathrm{~mm}$ & $10 \mathrm{~mm}$ & $8 \mathrm{~mm}$ & $16 \mathrm{~mm}$ & 1 & 0.8 & 1.2 \\
\hline
\end{tabular}

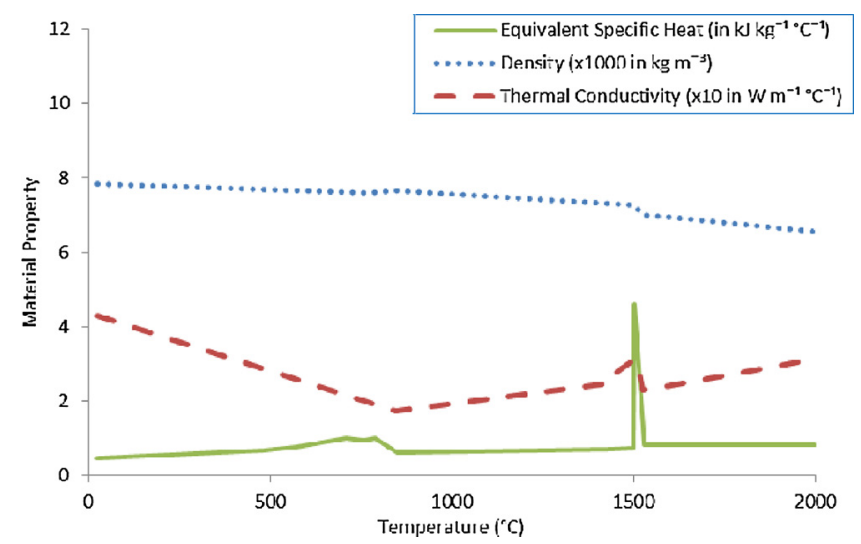

Fig. 5. Thermal material properties assumed for the base material S355G10 + M.

plates were used to prevent weld start and stop positions with potentially different properties in the examined plates.

Six K-type thermocouples welded to the base plate measured the temperature during the welding process. These thermocouples were positioned at the weld bead center line at 2, 5, 10, 20, 40 and $60 \mathrm{~mm}$ from the weld toe. A Yokogawa DL series recorder stored the temperature data with a sample rate of $5 \mathrm{~Hz}$.

Samples were taken after the welding procedure to examine the microstructure and Vickers Hardness of the bead-on-plate welded specimens. The average Vickers Hardness of the coarse and fine grained heat affected zone (cfHAZ) was equal to $344 \mathrm{HV}$. Both hardness value and microstructure correspond with the dilatometer test with cooling rate of $75^{\circ} \mathrm{C} / \mathrm{s}$ (Fig. 3).

\subsection{Thermal simulations}

The finite element software Abaqus CAE 6.14-1 (SIMULIA, 2012) with an Intel Fortran compiler was used for the numerical calculations. The dimensions of the finite element model match those of the tests, Fig. 6a. The three-dimensional 8-noded brick elements (DC3D8) have

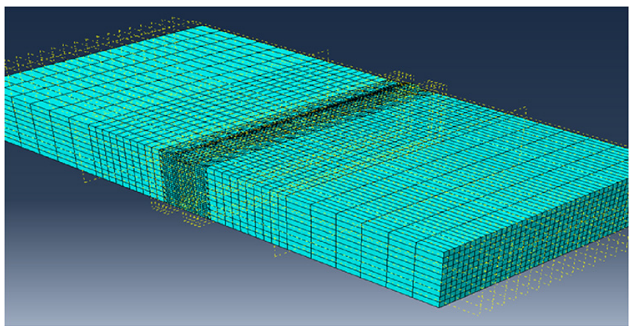

Fig. 7. Mesh of the finite element models.

dimensions of $5 \times 1 \times 1 \mathrm{~mm}$ (longitudinal, transverse and depth direction) near the weld arc and increased dimensions starting at $10 \mathrm{~mm}$ from the weld toe, Fig. 7.

The thermal analysis requires a heat input model that ignites a transient thermal analysis in the bead-on-plate welded specimen. The transient volumetric heat flux distribution model of Goldak (Goldak et al., 1984) resembles the excited energy distribution in the welded material by a moving arc and is implemented in the Abaqus subroutine DFLUX. This three-dimensional heat source model travels with the weld speed over the already deposited weld and base material in the longitudinal direction (x-direction). The total heat input $(Q)$, Eq. (1), is distributed by two, non-axisymmetric ellipsoidal volumetric source distributions expressed by Eqs. (2) and (3) that determine the transient heat flux distribution in front $\left(q_{v, f}\right)$ and rear $\left(q_{v, r}\right)$ of the heat source as a function of location $(x, y, z)$ and time $t$, see Fig. 8 . The total heat input is determined by the current $(I)$ and voltage $(U)$ level, the weld speed $(v)$ and the thermal efficiency $(\eta)$, the latter controlling the total heat input. Conduction is the dominant heat transfer mechanism for this weld geometry; the emissivity and convection coefficient were taken from (Van der Aa, 2007) and kept equal to $5 \mathrm{~W} \mathrm{~m}^{-2} \mathrm{~K}^{-1}$ and 0.7 respectively.

$Q=\frac{\eta U I}{v}$

$q_{v, f}(x, y, z, t)=\frac{6 \sqrt{3} Q f_{f}}{a b c_{1} \pi \sqrt{\pi}} e^{-3\left(\frac{x^{2}}{\left.a^{2}+\frac{y^{2}}{b^{2}}+\frac{(z-v t)^{2}}{c_{1}^{2}}\right)}\right.}$

$q_{v, r}(x, y, z, t)=\frac{6 \sqrt{3} Q f_{r}}{a b c_{2} \pi \sqrt{\pi}} e^{-3\left(\frac{x^{2}}{a^{2}}+\frac{y^{2}}{b^{2}}+\frac{(z-v t)^{2}}{c_{2}^{2}}\right)}$

The parameters $f_{f}$ and $f_{r}$ determine the fraction of the total heat input that is deposited at the rear or front of the heat source and are chosen as 0.8 and 1.2, respectively (Van der Aa, 2007). The geometrical heat source parameters $a, b, c_{1}$ and $c_{2}$ in Eqs. (2) and (3) determine the

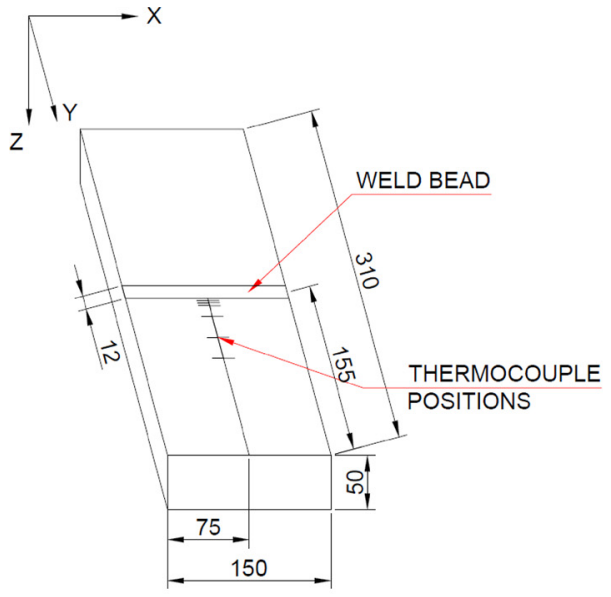

(a)

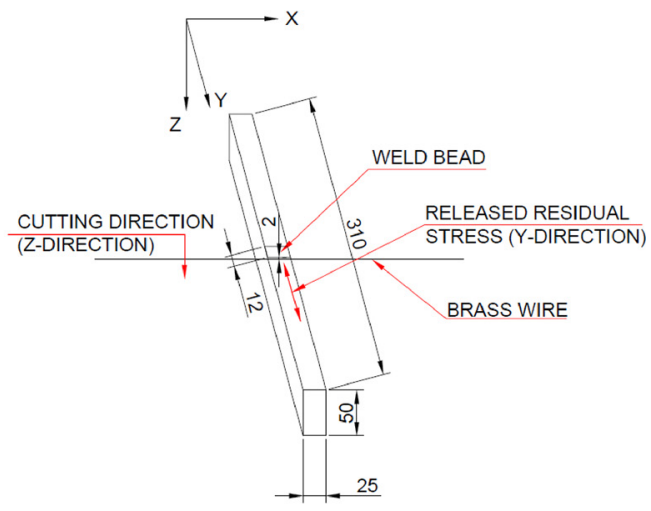

(b)

Fig. 6. Geometry of the specimens: (a) Entire specimen; (b) Specimen part in the crack compliance test. 


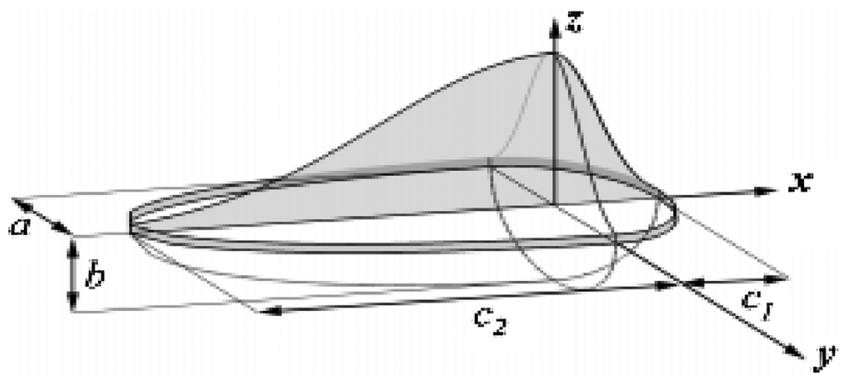

Fig. 8. Goldak heat source model (Goldak et al., 1984).

double ellipsoid volume size of the transient heat flux distributions. Their values were first approximated based on the weld bead profile measurement (Shan et al., 2009) by taking the semi bead width as $a$ $(6 \mathrm{~mm})$, total height as $b(6 \mathrm{~mm})$ and using $c_{1}=a$ and $c_{2}=2 a$. The values of these parameters and that of the thermal efficiency $(\eta)$ were subsequently calibrated using the temperature measurements. Table 3 provides the input parameters for the Goldak heat source model after calibration.

\subsection{Thermal results}

Fig. 9 provides the measured and simulated temperatures. The time $t=0$ corresponds to the arc ignition time on the run-on part. The thermocouple measurements are the average of the four welding specimens. A good agreement between the transient temperature distribution of the thermocouples and the numerical program is observed, indicating a general validity of the model and a sufficiently accurate calibration of model parameters of Eqs. (1)-(3).

Fig. 10 compares the macrograph of the specimen with the simulated peak temperature in the fusion zone. The figure shows a good agreement in shape but a slightly too small simulated size of the fusion zone, considering the liquidus temperature of $1530{ }^{\circ} \mathrm{C}$ (Section 2.2). At least one integration point of all of the DC3D8 elements that represent the cfHAZ experienced a peak temperature above the A3 temperature level.

Section 3.1 linked the Vickers Hardness of the cfHAZ to an average cooling rate of $75^{\circ} \mathrm{C} / \mathrm{s}$. The cooling rate in the finite element simulations at the weld toe and the weld bead symmetry line at a depth corresponding to the coarse and fine grained HAZ, were equal to $76^{\circ} \mathrm{C}$ / $\mathrm{s}$ and $69^{\circ} \mathrm{C} / \mathrm{s}$, respectively. The good agreement further attributes to confidence in the model.

\section{Mechanical analysis}

The through thickness residual stress distribution has been examined in this section using the crack compliance method and the welding simulations, using the thermal results and mechanical, material properties.

\subsection{Crack compliance experiment}

The crack compliance method was used to determine the residual stresses over the thickness of the plate. A Fanuc Series 310is-WA5 wire Electronic Discharge Machine (EDM) incrementally applied a crack over the full length $(25 \mathrm{~mm})$ of the bead-on-plate welded specimens, parallel to the weld direction, shown in Fig. 6b. These $25 \mathrm{~mm}$ long specimen were taken from the $150 \mathrm{~mm}$ weld bead plate (Fig. 6a). An initial notch of $0.6 \mathrm{~mm}$ depth was created and subsequently crack depth increments of $0.25 \mathrm{~mm}$ were applied up to a total crack depth of $20 \mathrm{~mm}$. From that depth onwards, crack depth increments of $0.5 \mathrm{~mm}$ were applied. The notch and resulting crack is applied at $2 \mathrm{~mm}$ from the weld toe to ensure that no inclusions or impurities are present in the cutting path. The same procedure was applied on a base plate. The cutting procedure created a fine slit that has almost no effect on the internal stress field (Prime, 2003).The residual stress perpendicular to the weld direction was released by applying this crack. Two strain gauges type WFLA-3-11-1 L applied at the bottom side of the specimen, at the crack center line, measured the redistribution of the residual stress field.

The measured strains were converted into residual stresses in the uncracked configuration using Linear Elastic Fracture Mechanics (LEFM) with a two-step approach:

- Eq. (4) relates the stress intensity factor $\left(K_{r s(a)}\right.$, ) to the measured strain $\left(\varepsilon_{m}\right)$ and crack depth $(a)$. The influence function $Z(a)$ derived by Schindler et al. (1997) takes into account the geometry, crack size, constraint configuration and relative position of the strain gauges. The appropriate constraint configuration accounts for plane stress $\left(E^{\prime}=E\right)$ or plane strain $\left(E^{\prime}=E /\left(1-\nu^{2}\right)\right), E$ is the modulus of elasticity and $\nu$ is the Poisson ratio.

$K_{r s(a)}=\frac{E^{\prime}}{Z(a)} \frac{d \varepsilon_{m}}{d a}$

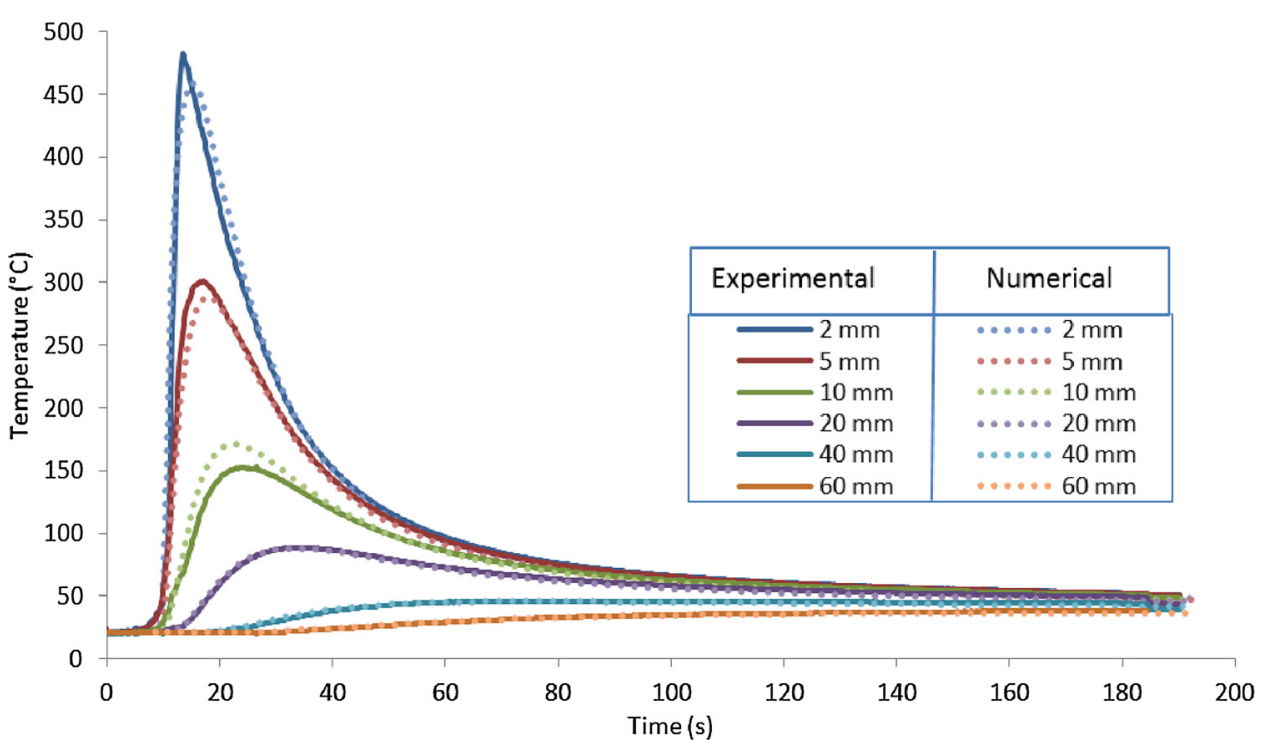

Fig. 9. Comparison between the measured and simulated temperatures (legend indicates distance between thermocouple and weld toe). 


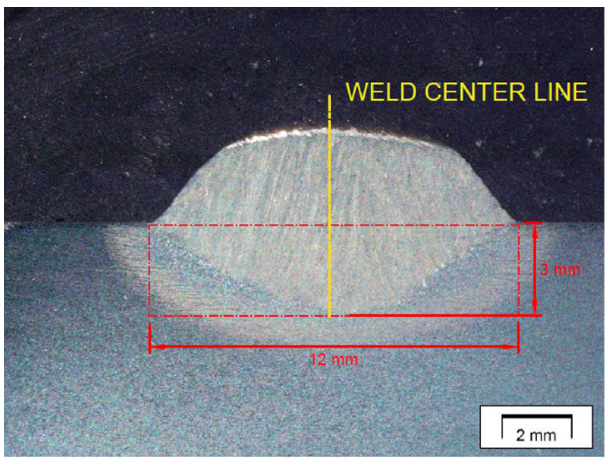

(a)

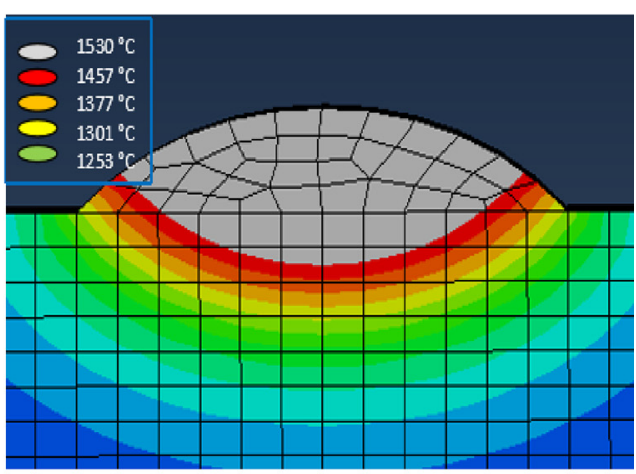

(b)

Fig. 10. Comparison between the fusion zone size: (a) obtained by metallurgical examinations, and (b) the experienced peak temperature in the numerical program.

- Eq. (5) represents Bueckner's weight function (Bueckner, 1970) and relates the stress intensity factor to the (residual) stress. The advantage of Bueckner's weight function is that it applies to an arbitrary stress state. The weight function $h(x, a)$ for a semi-infinite edge crack is taken from Wu and Carlsson (1991). The algorithm required to invert Eq. (5) is presented in (Schindler and Bertschinger, 1997). The weight function technique has a reduced accuracy at deep cracks (Schindler, 1993). The stress state is therefore provided up to $95 \%$ of the total depth of the specimens using Eqs. (4) and (5).

$K_{r s(a)}=\int_{0}^{a} h(x, a) \sigma_{r s}(x) d x$

Neglecting the initial residual stress state of the material before the welding procedure starts can jeopardize the validity of the finite element analysis, (Van der Aa, 2007). Especially high-strength steels produced by quenching and tempering are prone to residual stress formation during production. For these steels, the residual stresses should be determined and included as initial residual stress state in the numerical welding analysis, (Gao, 2014), (Hossain et al., 2004). Such studies have not been reported for thermo-mechanical rolled steels. Following the final rolling treatment at $800^{\circ} \mathrm{C}$, the material was cooled in air. The residual stress parallel to the rolling direction of the base material, deducted from the experiments, is shown in Fig. 11. The measured strains and resulting residual stress are low: maximum of 24 $.10^{-6}$ and $15 \mathrm{MPa}$, respectively, the latter being approximately $4 \%$ of the base material's yield stress at room temperature. Note that the accuracy of the measurement may be questioned at larger depths for these very low strain values. The results justify neglecting the base material's stress state in the finite element calculations

Two crack compliance tests were performed on the bead-on-plate welded specimens. The average difference between these two tests was $2 \%$ and the difference between the maximum residual stress values was

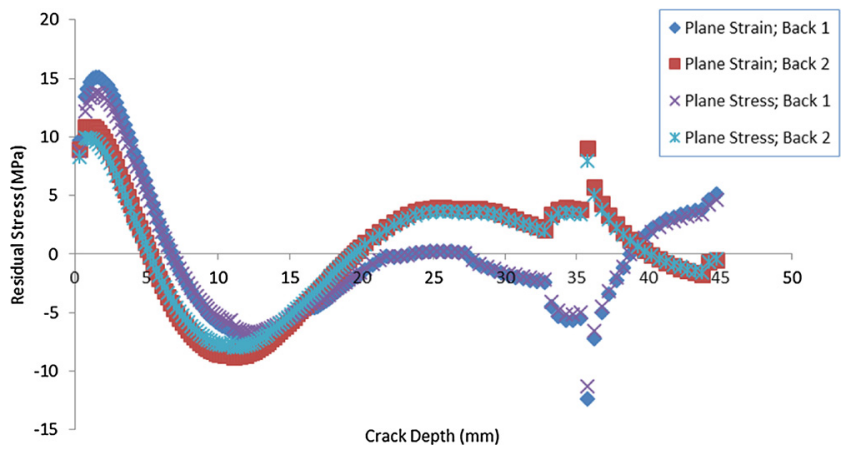

Fig. 11. Residual stress distributions of the base material parallel to the rolling direction.

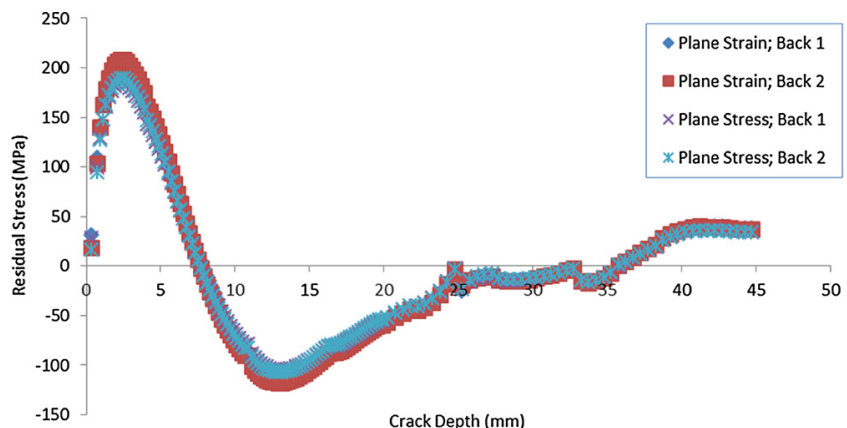

Fig. 12. Residual stress of the bead-on-plate welded specimen perpendicular to the weld direction at $2 \mathrm{~mm}$ from the weld toe.

also 2\%. Fig. 12 presents the residual stress state of one test for both plane strain and plane stress constraint assumptions. The maximum tensile stress is measured in the sub-surface region and is equal to $210 \mathrm{MPa}$, or $54 \%$ of the base material yield stress at room temperature for the plane strain assumption and slightly lower for the plane stress assumption. A balancing compression stress is present in the core. The angular distortion caused by welding provides a tensile stress at the bottom side. The maximum base material residual stress is $7 \%$ of the residual stress of the bead-on-plate welded specimen.

\subsection{Mechanical simulations}

The residual stress formation was simulated using the mesh of Fig. 7 and the three-dimensional transient temperature distribution of the prior thermal analysis. Eight-noded brick elements with a reduced integration scheme (C3D8R) were applied for the mechanical analysis. The two analyses were decoupled, assuming that the mechanical analysis does not influence the thermal analysis, which implies neglecting the heat generation during the plastic deformation of steel. Fig. 13 gives an outline of the numerical analysis. Using the dilatometer experiments, the temperature increments were transferred into thermal strain increments. A Fortran subroutine UEXPAN was developed for this purpose. The thermal strain increments were subsequently transferred into stress increments, using the tensile test results and assuming the isotropic Von Mises yield locus. An Abaqus built-in implicit return-mapping algorithm updated the total stress vector after each temperature increment. Constraints due to specimen clamping and weld deposition are expected to have a negligible influence on the residual stresses because of the large plate thickness of the current application. The weld bead was therefore applied in the finite element geometry prior to the analysis, i.e. not physically added as in the welding procedure.

The total thermal strain $\left(\varepsilon_{t h, t o t}\right)$ is the sum of linear thermal expansion $\left(\varepsilon_{t h}\right)$ and a volumetric strain component $\left(\varepsilon_{v o l}\right)$, the latter depending 


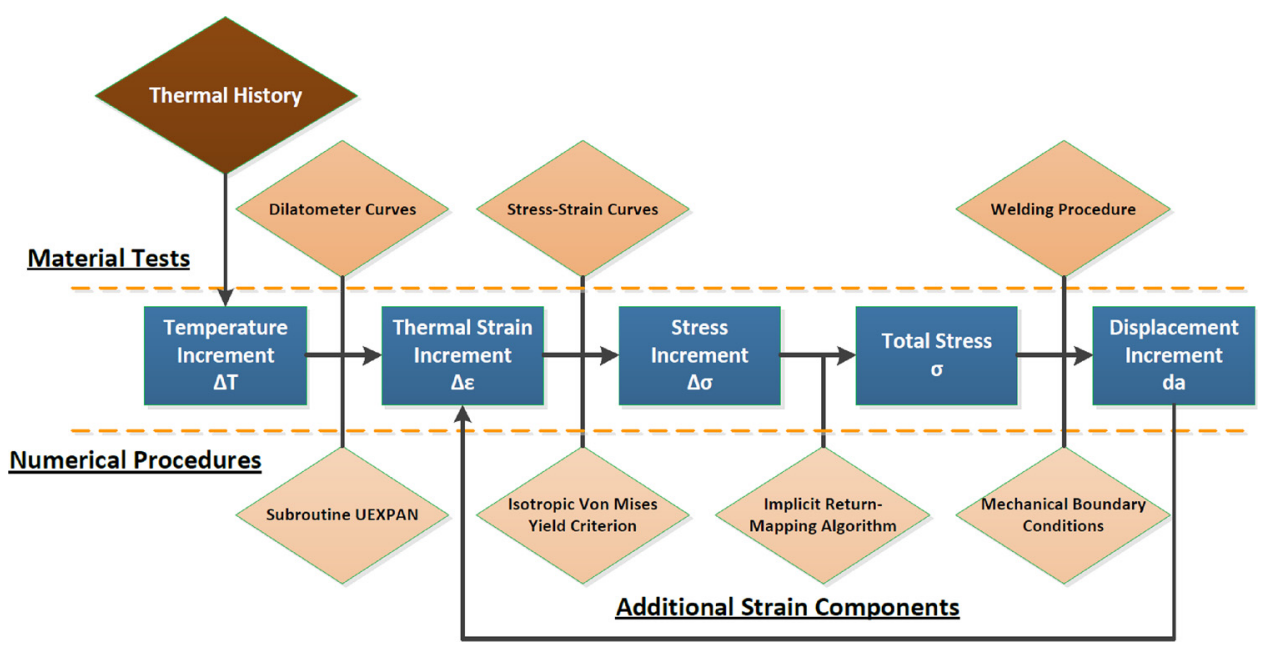

Fig. 13. Numerical procedure of the mechanical analysis to calculate the residual stress.

on the temperature $(T)$, exposure time $(t)$ and cooling rate $(t)$ :

$\varepsilon_{t h, t o t}(T, t, \dot{t})=\varepsilon_{t h}(T)+\varepsilon_{v o l}(T, t, \dot{t})$

The volumetric strain component is considered for cooling only and incomplete phase transformations are ignored. Consequently it applies to regions that experienced a peak temperature exceeding the A3 temperature.

The fast and exponential volumetric strain experienced during cooling in the dilatometer tests as well as the microstructure after the tests indicate transformation from austenite (phase 2) to a mixture of ferrite, bainite and martensite (phase 1). The Koistinen-Marburger equation (Koistinen and Marburger, 1959) is able to describe the accompanying phase transformation kinetics between the phase start and finish temperature levels:

$P_{1}(T)=\left(1-\exp \left(-b\left(M_{S}-T\right)\right)\right)$

where $P_{1}$ is the fraction of phase $1, M_{s}$ is the martensite formation start temperature and $b$ is the martensite growth parameter. Piekarska et al. (2011) related the martensite growth parameter to the martensite start and finish $\left(M_{f}\right)$ temperatures:

$b=-\frac{\ln 0.01}{M_{s}-M_{f}}$

For the applicable cooling rate of $75{ }^{\circ} \mathrm{C} / \mathrm{s}$, the martensite formation start and finish temperatures are $M_{s}=480{ }^{\circ} \mathrm{C}$ and $M_{f}=320^{\circ} \mathrm{C}$, respectively.

In agreement with Caron et al (Caron et al., 2010), the KoistinenMarburger equation was used in the current work for the entire transition from phase 2 to 1 during cooling, rather than just the formation of martensite. The phase transformation is therefore described with Eqs. (9)-(10) for the full welding thermal cycle. A linear phase transformation is considered during heating between $\mathrm{A} 1=735^{\circ} \mathrm{C}$ and $\mathrm{A} 3=885.5^{\circ} \mathrm{C}$. The microstructural composition outside these temperature ranges is either fully austenitic (phase 2) or fully mixed morphology (phase 1). As an example, Fig. 14 illustrates the phase transformation for an arbitrary temperature profile exceeding the A3 temperature.

$P_{1}(T)=\left\{\begin{array}{c}P_{1}=\frac{T-A_{3}}{A_{1}-A_{3}} A_{1}<T\left\langle A_{3} \text { and } \Delta T\right\rangle 0 \\ P_{1}=\left(1-\exp \left(-b\left(M_{s}-T\right)\right)\right) M_{f}<T<M_{s} \text { and } \Delta T<0\end{array}\right.$

$P_{2}(T)=1-P_{1}(T)$

The strain associated with linear thermal expansion $\left(\varepsilon_{t h}\right)$ is related to the phase fractions $\left(P_{i}\right)$ and their corresponding linear thermal expansion coefficients $\left(\alpha_{i}\right)$, using the linear mixing rule of (Gao, 2014):

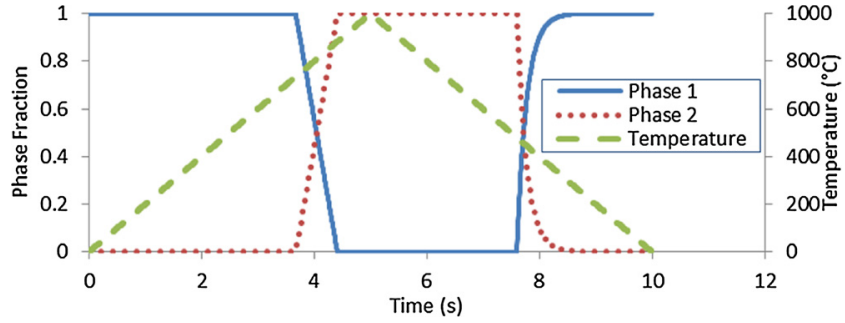

Fig. 14. Phase transformation during heating and cooling for a linear temperature profile.

$\varepsilon_{t h}(T)=\sum_{i=1}^{2} P_{i}(T) \alpha_{i} \Delta T$

The phase fractions and their specific volumes $\left(V_{i}\right)$ determine the specific volume $(V)$ and the specific volume change $\Delta V$ of the dualphase steel:

$V(T)=\sum_{i=1}^{\text {nPhases }=2} V_{i} P_{i}(T)$

$\Delta V(T)=\sum_{i=1}^{n \text { Phases }=2} V_{i} \Delta P_{i}(T)$

The volumetric strain component per (principal) stress direction is provided with Eq. (14), where $V_{\text {Start }}$ is the initial specific volume of the base material. Isotropic material behavior was assumed. The specific volumes of the individual phases were obtained by calibrating the linear mixing procedure to the dilatometer results, Fig. 15. The model was subsequently corrected, by disregarding the difference in dimensions at the start and finish of the test (Korevaar and Pennekamp, 1984), Fig. 15.

$\varepsilon_{\text {vol }}(T)=\frac{1}{3} \frac{\Delta V(T)}{V_{\text {Start }}}$

The accumulated thermal strains in the fusion zone required a reset to zero during the solid-liquid transition (Cheng, 2005). This research neglected the strain development in the fusion zone during heating and considered contraction during cooling only. Reason is that the fusion zone is relatively small in this single weld-pass geometry, so expansion of the fusion zone during heating has minor effect on the stress development in surrounding regions.

An isotropic hardening plasticity model was used to convert the thermal strain increments into stress increments. The true stress-strains relations resulting from the tensile tests were used to create a 


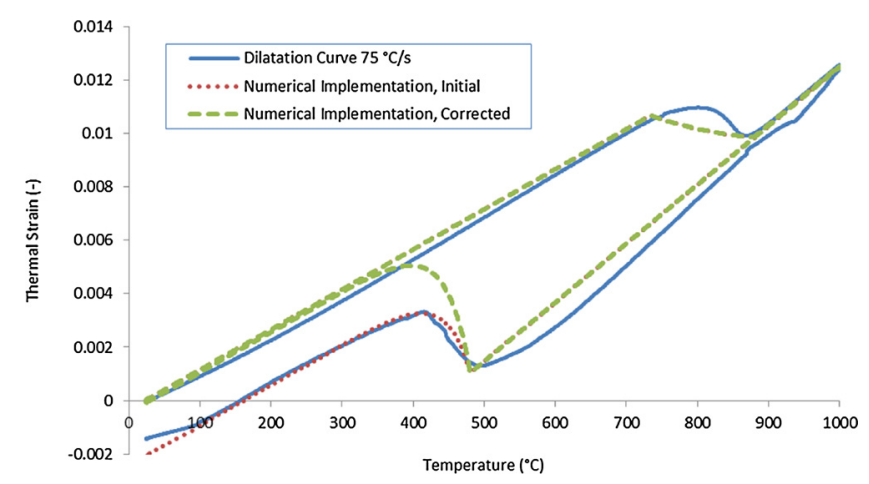

Fig. 15. The dilatation curve of $75^{\circ} \mathrm{C} / \mathrm{s}$ with the corresponding numerical implementation.

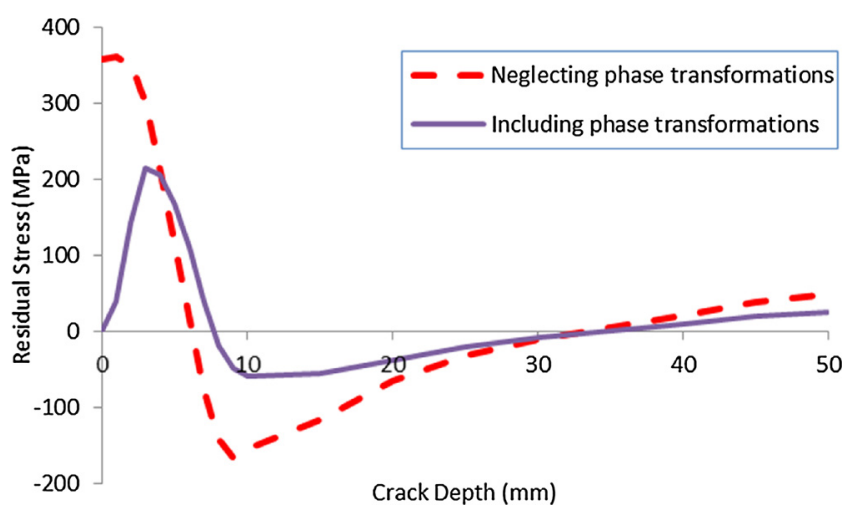

Fig. 16. Through-thickness residual stress distribution, perpendicular to the weld direction for the situation with and without phase transformations.

temperature dependent Von Mises yield locus. Kinematic hardening (Sonne et al., 2012) and creep effects (Bastier et al., 2006) are important in multiple-pass welding due to multiple thermo-mechanical loading cycles and long exposure times. For the current application with a single weld pass, however, this was not considered being important. The strain rate of $0.0003851 / \mathrm{s}$ used in the tensile tests was lower than the rates encountered during welding. Van der Aa (2007) concluded that too low strain rates may underestimate the material properties at elevated temperature. This could result in underestimated residual stresses obtained in the numerical procedures. In addition, the strength may depend on the heat treatment in the welding thermal cycle (i.e phase transformations, grain refinement etcetera) but was not included in the current research. These limitations may cause a small deviation between simulation and reality.

\subsection{Structural results}

The residual stress was examined at $2 \mathrm{~mm}$ from the weld toe, perpendicular to the weld direction and over the full depth of the specimens, equal to the location examined in the crack compliance experiments.

Two different models were analyzed with the results presented in Fig. 16:

- Neglecting phase transformations: Only linear thermal expansion is considered. The fusion zone expands and contracts without a reset of accumulated plastic strain at the liquidus temperature of the base material.

- Including phase transformations: Elements are sorted in three groups. Group 1 contains all elements that encounter a maximum temperature level exceeding the liquidus temperature level $\left(1530{ }^{\circ} \mathrm{C}\right)$. These elements do not expand during heating, but they do contract and are subjected to a phase transformation (with the associated volumetric strain component) during cooling. Group 2 contains all elements with a maximum temperature between 1530 and $\mathrm{A} 3=883.5^{\circ} \mathrm{C}$. These elements expand during heating and are exposed to the phase transformation during cooling. Group 3 contain the remaining elements, which are not subjected to phase transformations and only linear thermal expansion is considered.

Fig. 16 indicates that the phase transformation significantly affects the residual stress formation, especially in the near-surface region. The surface values are $+359 \mathrm{MPa}$ and $+3 \mathrm{MPa}$ for the situation without and with phase transformations, respectively. The combination of the large volumetric strain and relatively low steel temperatures - and therefore relatively high strength and stiffness - raises the necessity of including phase transformations. The volume expansion is opposed by the surrounding material, which reduces the tensile stresses in the nearsurface region near the weld toe.

The residual stresses are in a self-equilibrium state due to the absence of an external load. The balancing compression stress in the core of the specimens is therefore lower for the case with a lower tensile stress at the surface. The distortions are relatively small due to the large section modulus of the thick plate. A bending stress developed, however, due to deposition of molten material at the surface and the resulting contraction of this material. This results in a tensile stress at the bottom fibers.

The numerical results of Fig. 16 are compared to the experimental crack compliance results in Fig. 17 at $2 \mathrm{~mm}$ from the weld toe. A good agreement is observed between the finite element results that included

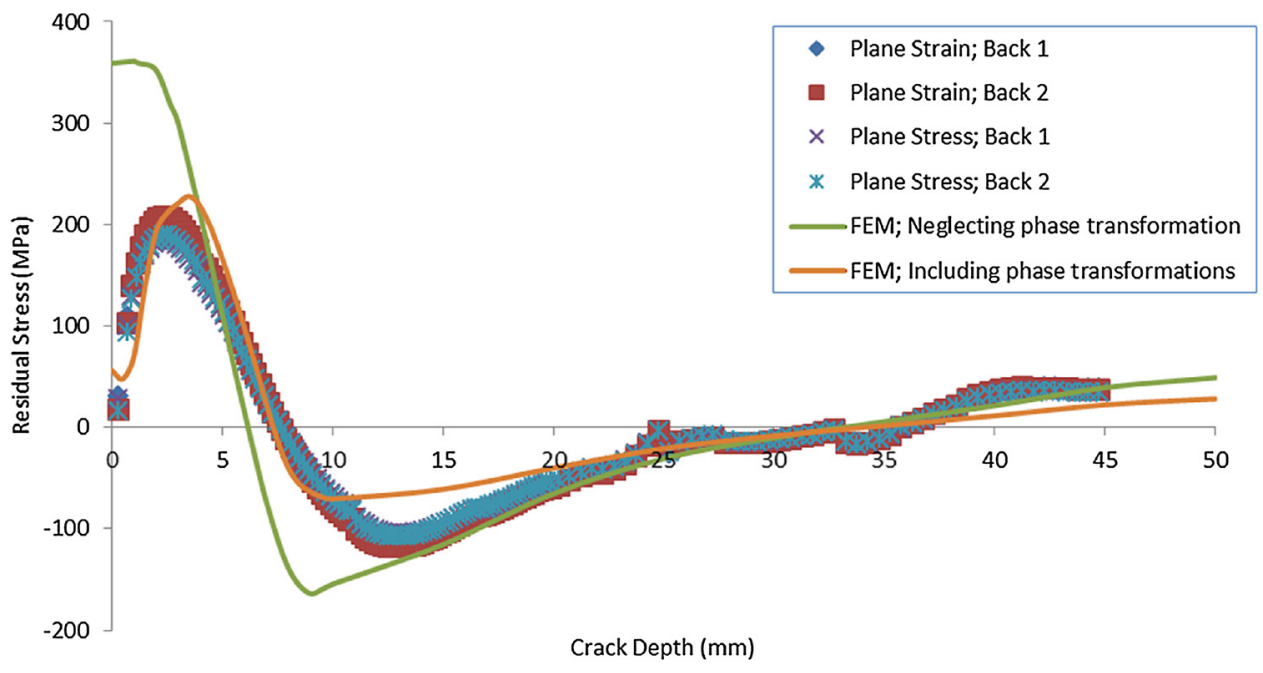

Fig. 17. Comparison between numerical and experimental residual stress distribution. 
the phase transformations and the crack compliance method results. The latter observation shows the importance of including phase transformations during cooling in welding applications with high cooling rates. These results show that an accurate prediction of residual stresses is possible if the material properties of steel are known or studied and if the weld temperature input is calibrated with tests.

\section{Conclusion}

This study provides insight into the role of phase transformations and the associated volumetric strains in the formation of residual stress caused by welding. An accurate prediction of the though-thickness residual stress state is possible when combining detailed material research, thermal analysis and sound mechanical simulation of a weld procedure. The main conclusions of this research are:

- The solid-solid phase transition during cooling in a weld procedure can have a large influence on the magnitude of the residual stress. For the bead-on-plate specimen examined here, the phase transition reduced the maximum residual stress with more than $50 \%$. Phase transitions must therefore be considered in predictions of residual stresses for welding configurations with high cooling rates.

- The thermo-mechanical rolling treatment, used to produce the $50 \mathrm{~mm}$ thick S355G10 + M base material, hardly introduced residual stress perpendicular to the rolling direction.

- The crack compliance method, using a wire EDM machine and a LEFM based approach to manipulate the data, is an accurate and useful procedure to study though-thickness residual stresses.

\section{Acknowledgement}

The authors acknowledge the TU Delft research groups chaired by Milan Veljkovic and Ian Richardson for their advices and access to experimental facilities. The authors are in particular grateful for the contribution of Marcel Hermans, Peter de Vries and Abdulkadir Akyel to this research.

\section{References}

ASTM International, 2012. ASTM E112-12; Standard Test Methods for Determining Average Grain Size. ASTM International, West Consohocken, United States of America.

ASTM International, 2016. E384-16 Standard Test Method for Micorindentation Hardness of Materials. ASTM International, West Conshohocken, United States of America.

Bastier, A., Maitournam, M.H., Roger, F., Dang Van, K., 2006. Modelling of the residual state of friction stir welded plates. J. Mater. Process. Technol. 200, 25-37.

Bhadehsia, H.K.D.H., 2006. Steel; Microstructure and Properties. Elsevier, Oxford, United Kingdom.

Bueckner, H.F., 1970. A novel principle for the computation of stress intensity factors. Zeischrift fur angewandte Mathematik und Mechanik 50.

Caron, J., Heinze, C., Schwenk, C., Rethmeier, M., Babu, S.S., Lippold, J., 2010. Effect of continuous cooling transformation variations on numerical calculation of weldinginduced residual stresses. Weld. J. 89 (July), 151-160.

Cheng, W., 2005. PhD Thesis; In-Plane Shrinkage Strains and their Effects on Welding Distortion in Thin-walled Structures. Ohio State University, Ohio, United States of
America.

Depradeux, L., Coquard, R., 2017. Influence of viscoplasticity, hardening, and annealing effects during the welding of a three-pass slot weld (NET-TG4 round robin). Int. Press. Vessels Pip In Press.

Gao, H., 2014. PhD Thesis: Residual Stress Developments Due to High-Frequency Post Weld Impacts Treatments for High-Strength Steels. TU Delft, Delft.

Goldak, John A., Akhlaghi, Mehdi., 2005. Computational Welding Mechanics. Springer, Ottawa, Canada.

Goldak, John, Chakravarti, Aditha, Bibby, Malcolm., 1984. A New finite element model for welding heat sources. Carketon Univ. Can. Metall. Trans. B 15B (June), 1984.

Guo, Zhanli, Saunders, Nigel, Miodownik, Peter, Schille, Jean-Philippe, 2009. Modelling phase transformations and material properties critical to the prediction of distortions during the heat treatments of steel. Int. J. Microstruct. Mater. Prop. 4, 187-195.

Hossain, S., Daymond, M.R., Truman, C.E., Smith, D.J., 2004. Prediction and measurement of residual stresses in quenched stainless-steel members. Mater. Sci. Eng. A 373, 339-349.

Kaushik Dutta, Rangan, 2015. PhD Thesis; Microstructural Evolution During HighFrequency Post Weld Impact Treatments for High-Strength Steels. TU Delft, Delft, The Netherlands.

Koistinen, D.P., Marburger, R.E., 1959. A general equation prescribing the extent of the austenite-martensite transformation in pure iron-carbon alloys and plain carbon steels. Acta Metall. 7, 59-60.

Korevaar, Dr.Ir.B.M., Pennekamp, Ir.B., 1984. Mt 7a; Materiaalkunde 2, Staal en Gietijzer. Faculteit der Metaalkunde. TU Delft, Delft.

Muransky, O., Hamelin, C.J., Smith, M.C., Bendeich, P.J., Edwards, L., 2012. The effect of plasticity theory on predicted residual stress fiels in numerical weld analyses. Comp. Mater. Sci. 54, 125-134.

Muransky, O., Hamelin, C.J., Patel, V.I., Luzin, V., Braham, C., 2015. The influence of constitutive models of accumulated plastic strain in finite element weld analyses. Int. J. Solids Struct. 69-70, 518-530.

Piekarska, W., Kubiak, M., Bokota, A., 2011. Numerical simulation of thermal phenomena and phase transformations in laser-arc hybrid welded joints. Arch. Metall. Mater. 56, 409-421.

Prime, Michael B., 2003. Experimental Procedure for Crack Compliance (Slitting) Measurements of Residual Stresses. Los Alamos National Laboratory, Los Alamos, United States of America.

Saunders, N., Guo, Z., Li, X., Miodownik, A.P., Schille, J.-Ph., 2003. Using JMatPro to model materials properties and behavior. JOM 60-65.

Schindler, H.J., 1993. Weight functions for deep cracks and high stress gradients. Adv. Fract. Resistance Struct. Integr. 8, 191-205.

Schindler, Hans-Jakob, Bertschinger, Peter., 1997. Some Steps Towards Automation of the Crack Compliance Method to Measure Residual Stress Distributions. Swiss Federal Laboratories for Materials Testing and Research, Dubendorf, Switserland.

Schindler, H.J., Cheng, W., Finnie, I., 1997. Experimental determination of stress intensity factors due to residual stresses. Exp. Mech. 37, 272-277.

Sente Software Limited, 2005. JMatPro User's Guide 4.0.

Shan, X., Davies, C.M., Wangsdan, T., O’Dowd, N.P., Nikbin, K.M., 2009. Thermo-mechanical modelling of a single-bead-on-plate weld using the finite element method. Int. J. Press. Vessels Pip. 86, 110-121.

SIMULIA, 2012. Abaqus Analysis User's Manual 6.12.

Sonne, M.R., Tutm, C.C., Hattel, J.H., Simar, A., De Meester, B., 2012. The effect of hardening laws and thermal softening on modelling residual stresses in FSW of aluminium alloy 2024-T3. J. Mater. Process. Technol. 213, 477-486.

Van der Aa, E., 2007. PhD Thesis; Local Cooling During Welding: Prediction and Control of Residual Stresses and Buckling Distortion. TU Delft, Delft.

Van der Wolk, Pieter J., Wang, Jiajun, Sietsma, Jilt, Van der Zwaag, Sybrand., 2002a. Modelling of Continuous Cooling Transformation Diagram of Engineering Steels using Neural Networks. Part 1: Phase Regions. TU Delft, Delft, The Netherlands.

Van der Wolk, Pieter J., Wang, Jiajun, Sietsma, Jilt, Van der Zwaag, Sybrand., 2002b. Modelling of Continuous Cooling Transformation Diagram of Engineering Steels using Neural Networks. Part 2: Microstructures and Hardness. TU Delft, Delft, The Netherlands.

Wohlfart, H., Nitschke-Pagel, Th., Dilger, K., Siegele, D., Brand, M., Sakkiettibutra, J., Loose, T., 2012. Residual stress calculations and measurements - review and assessment of the IIW round robin results. Weld. World 56, 120-140.

Wu, Xue-ren, Carlsson, Janne, 1991. Weight Functions and Stress Intensity Factor Solutions. Pergamon Press, Univerisy of Michigan, United States of America. 